\title{
Pressure Specified Sensory Device
}

National Cancer Institute

\section{Source}

National Cancer Institute. Pressure Specified Sensory Device. NCI Thesaurus. Code C156189.

A computer-based quantitative sensory testing device that detects cutaneous pressure perception and two-point discrimination. It is designed to quantify and record both specific peripheral nerve threshold levels and peripheral nerve innervation density. 